\title{
Acessibilidade e Inclusão Digital de Cegos e Surdos em Plataformas Web: um estudo de caso
}

\author{
Camila Freitas Sarmento ${ }^{1}$, Herbert Costa do Rego ${ }^{2}$ \\ ${ }^{1}$ Departamento de Computação - Universidade Federal de Campina Grande (UFCG) \\ Rua Aprígio Veloso, 882, Universitário - 58.429-900 - Campina Grande - PB - Brazil \\ ${ }^{2}$ Centro de Educação - Universidade Estadual da Paraíba (UEPB) \\ Rua Baraúnas, 351, Universitário - 58.429-500 - Campina Grande - PB - Brazil \\ camilasarmento@copin.ufcg.edu.br, hcrego@gmail.com
}

\begin{abstract}
This article describes a web platform developed in HTML5, CSS3 and JavaScript with the aim of facilitating the inclusion of blind and deaf students in the teaching of the computer course, it is an innovative action aimed at the professional training of students with visual and hearing disabilities, within the legal parameters that provides for an inclusive education. For that, a didactic material was developed in the format of video lesson, in Pounds and with audiodescription of the commands of the screen reader Virtual Vision - version 7.0, for the use of Microsoft Office 2010 applications (Word, Excel, Power Point) and of Internet, related to the course of Microcomputer Operator.
\end{abstract}

Resumo. Este artigo descreve uma plataforma web desenvolvida em HTML5, CSS3 e JavaScript com o objetivo de facilitar a inclusão de alunos cegos e surdos no ensino do curso de informática, trata-se de uma ação inovadora direcionada à formação profissional de alunos com deficiência visual e auditiva, dentro dos parâmetros legais que prevê uma educação inclusiva. Para tanto, foi desenvolvido um material didático no formato de vídeo aula, em Libras e com audiodescrição dos comandos do leitor de tela Virtual Vision - versão 7.0, para o uso dos aplicativos do Microsoft Office 2010 (Word, Excel, Power Point) e de Internet, relacionados ao curso de Operador de Microcomputador.

\section{Introdução}

No Brasil, a Constituição de 1988 [Brasil, 1988] elencou vários dispositivos referentes aos direitos das pessoas com deficiência, na esfera da saúde, educação, trabalho e assistência. Em dezembro de 2004 foi assinado, no Brasil, um decreto-lei que estabelece um prazo de doze meses para a adequação de todo portal ou site eletrônico da administração pública, de interesse público ou financiado pelo governo. Diante desse contexto, foi estabelecido um comitê (CB-40) da Associação Brasileira de Normas Técnicas que desenvolveu um Modelo de Acessibilidade Brasileiro (eMAG) para viabilizar o acesso facilitado a qualquer pessoa, independente das condições físicas, dos meios técnicos ou dispositivos utilizados. Silva et al. (2012) realizou uma pesquisa acerca da acessibilidade digital em ambientes virtuais de aprendizagem para indivíduos com deficiência visual e concluiu que apesar da existência de recomendações de 
padrões web (e.g., o World Wide Web Consortium - W3C que possui como principal área de atividade a iniciativa da acessibilidade na web conhecida como Web Accebility Iniative - WAI); avaliadores de sites (e.g., DaSilva, Hera e o Examinator) que norteiam os desenvolvedores de ambientes na web, ainda assim, há barreiras que os deficientes visuais e cegos encontram com relação ao acesso web.

O presente artigo além de abordar o desenvolvimento e validação de uma plataforma web para o ensino-aprendizagem de indivíduos surdos e cegos, apresenta um estudo acerca da importância do desenvolvimento de ambientes web acessíveis para que ocorra a inclusão digital e que pessoas com necessidades especiais também tenham recursos de aprendizagem, informação e entretenimento. Ao final, apresentam-se os resultados dos grupos de alunos com deficiência visual/auditiva que utilizaram a plataforma web comparados aos que utilizaram outros métodos de ensino online; um breve relato de experiência em relação ao desenvolvimento da plataforma e das variáveis de dificultam o estudo em ambientes web. Ao final, formula-se a conclusão crítica sobre os resultados encontrados com este estudo.

\section{Estudo de caso}

Os resultados do Censo Demográfico de 2010 do Instituto Brasileiro de Geografia e Estatística (IBGE) apontaram uma população total para o Brasil de 190.732.694 pessoas. Revelaram também que 45,6 milhões dentre estas pessoas tinham algum tipo de deficiência, o que correspondia a $23,91 \%$ da população brasileira. Para tanto, a Tecnologia da Informação oferece várias oportunidades de inclusão digital para que pessoas com deficiência, ou não, possam se beneficiar dos recursos computacionais [Ferreira et al., 2007; BALANSIN, 2011].

No caso do acesso a páginas web, o acesso de um indivíduo portador de deficiência visual, necessita de apoio que consiste de softwares denominados "leitores de tela", tais como: o (i) Dosvox ${ }^{1}$; o Virtual Vision ${ }^{2}$ e $\mathrm{Orca}^{3}$. Ainda assim, apesar de normas técnicas (e.g., W3C e eMAG) serem recomendadas para o desenvolvimento de sites web, alguns leitores de tela não possuem um bom desempenho devido à falta de descrição de imagens, vídeos, entre outros conteúdos [DA PAIXÃO, 2015].

\section{Materiais e métodos}

Considerando a evasão de alunos PCDs (Pessoas com Deficiência) matriculadas nos cursos de educação profissional no âmbito do SENAI - PB (Serviço Nacional de Aprendizagem Industrial da Paraíba), realizou-se uma pesquisa in loco com os alunos que possuíam deficiência visual (em qualquer grau) e surdos por meio de questionários não-estruturados acerca das dificuldades no aprendizado e qualificação profissional a fim de obter uma perspectiva de quais variáveis que dificultam o estudo em ambientes web. Sendo assim, as maiores queixas para os deficientes visuais foi o leitor de tela que não realizava a leitura da tela à exemplo de gráficos e imagens disponibilizadas na web;

\footnotetext{
${ }^{1}$ http://intervox.nce.ufrj.br/dosvox/intro.htm

${ }^{2} \mathrm{http}: / /$ www.virtualvision.com.br/

${ }^{3}$ http://live.gnome.org/Orca
} 
VI Congresso Brasileiro de Informática na Educação (CBIE 2017)

Anais do XXVIII Simpósio Brasileiro de Informática na Educação (SBIE 2017)

no caso dos indivíduos surdos, o maior problema foi a falta da linguagem de sinais para os textos longos, pois, para o surdo, a leitura textual se torna cansativa e falha de compreensão.

Então, para isso, realizou-se uma adequação de material didático impresso e foi inserido na plataforma web imagens ampliadas para os surdos e somente sons para os cegos. As normas disponíveis na LDB e na Lei de Acessibilidade $\mathrm{n}^{\circ} 10.098 / 2000$ no seu artigo $2^{\circ}$ foram cumpridas e utilizou-se as tecnologias de HTML5, CSS3 e JavaScript utilizando as recomendações de padrões web com as tags sugeridas pela Web Accebility Iniative - WAI. Para a adequação, foram utilizados três pontos de vista, a saber: (i) da indústria, expresso por um diagnóstico do processo interativo por um especialista, com base nas recomendações do Modelo de Acessibilidade Brasileiro (eMAG); (ii) do especialista, expresso sob a forma de uma análise do desempenho do usuário durante a realização das tarefas utilizando a aplicação; e (iii) do usuário, expresso pela visão do usuário sobre o processo interativo com a aplicação.

Após a finalização da plataforma web (sob o ponto de vista da indústria e do especialista), houve uma validação baseada sob o ponto de vista do usuário fundamentada em três métodos: observação direta, administração de questionário pósteste e entrevista com os usuários. O estudo contou 40 indivíduos portadores de deficiência visual ou auditiva. A validação do material ocorreu após a aplicabilidade do curso em duas turmas de pessoas com deficiência visual e/ou auditiva. Os resultados dos indicadores de mensuração de desempenho (eficiência e eficácia) apontaram que o desempenho dos alunos que utilizaram a plataforma era superior aos comparados com alunos que fizeram o curso sem a plataforma da forma tradicional de ensino. Também foi observado que o índice de evasão do curso da turma que utilizou a plataforma web foi $50 \%$ inferior em comparação aos que não utilizaram.

\section{Conclusão}

O material didático proporcionou a eliminação de obstáculos no processo de aprendizagem do aluno com deficiência, considerando um impacto significativamente social. Além de proporcionar condições para o processo de inclusão, garantindo dignidade para o trabalhador, evitando assim que a contratação de PcDs seja apenas por uma determinação de lei, mas uma ação inclusiva de um profissional qualificado.

\section{References}

BALANSIN, C. F. (2011) "Especificação e Implementação de um Leitor de Tela", Unioeste - Universidade Estadual do Oeste do Paraná. Monografia. http://www.inf.unioeste.br/ tcc/2011/TCC-Cleiton.pdf. Maio.

BRASIL, Constituição (1988) "Constituição da República Federativa do Brasil", Brasilia, DF: Senado Federal: Centro Gráfico, 1988, 292p. http://bd.camara.gov.br/bd/, maio.

DA PAIXÃO, A. S. e DA SILVA, C. V. M. (2015). "A funcionalidade de softwares leitores de tela a partir de uma webquest interdisciplinar." Revista Trilha Digital 2.1.

SILVA, S. (2012) “Acessibilidade Digital em Ambientes de Aprendizagem”, In: Revista GEINTEC - Gestão, Inovação e Tecnologias, vol.2. Ed. 3, pages 245-254. 